\title{
Age of Initiation and the Factors Associated with Toilet Training in Healthy Saudi Children
}

\author{
Hamdan H. Al-Hazmi ${ }^{1}$, MD, SBU, Fahad A. Al-Yami ${ }^{1}$, MD, FRCSC, \\ Raed M. Almannie', MD, FRCSC, Jawaher S. Al-Emran², Mashael A. Hussain², \\ Rana F. Alhumaemydi' ${ }^{2}$, Sara S. Aljebrin ${ }^{2}$, Aljohara K. Aldhaish ${ }^{2}$, \\ and Mahmoud S. Trbay ${ }^{1}$, MSc, MRCS \\ 'Department of Surgery, Division of Urology, College of Medicine and King Saud University Medical City, \\ King Saud University, Riyadh, Saudi Arabia \\ ${ }^{2}$ Medical Student, College of Medicine, King Saud University, Riyadh, Saudi Arabia
}

\section{Correspondence \\ Dr. Hamdan H. Al-Hazmi \\ P.O. Box 7805 \\ Riyadh 11472 \\ Kingdom of Saudi Arabia \\ e-Mail: drhamdan@ksu.edu.sa \\ Submission: 21 Jan 2018 \\ Accepted: $\quad 07$ Feb 2018}

\section{Citation}

Al-Hazmi HH, Al-Yami FA, Almannie RM, AlEmran JS, Hussain MA, Alhumaemydi RF, Aljebrin SS, Aldhaish AK, and Trbay MS. Age of initiation and the factors associated with toilet training in healthy Saudi children. JKAU Med Sci 2018; 25 (1): 15-22. DOl: 10.4197/Med. 25.1.3

\begin{abstract}
With the appropriate knowledge of the age to initiate toilet training and acknowledging the factors that influence it, parents can prevent many health issues related to voiding. Our study aimed to determine the average age of the initiation of toilet training among Saudi children and the factors that may affect this training. This study was carried out by distributing questionnaires to mothers who attended various clinics in our institute. A sample included 1000 healthy Saudi children. The mean age of the initiation of toilet training in healthy children was 25.6 \pm 9.4 months while the median was 24 months, the mean duration of training was $6.3 \pm 9.1$ months. Most children (92\%) were trained in the summer months. Mother's educational level, number of siblings, and socioeconomic status were significant factors that affected the age of initiation. However, mother's occupation, caregiver, and the order and gender of the child did not have a significant effect on the initiation of toilet training. The median age of toilet training among our children matched other studies. Summer seems to be the preferred season to initiate training.
\end{abstract}

\section{Keywords}

Toilet training; Educational status; Child development; Training activity; Age of onset

\section{Introduction}

$T$ oilet training is one of the most crucial milestones in a child's development. In the recent years, the age of toilet training initiation has decreased tremendously with more parents leaning towards early training as it makes their children more self-dependent ${ }^{[1-4]}$ Toilet training is a complicated process that requires time and effort. There are multiple interplaying factors, including pathological, physiological, cultural, and socioeconomic status that could make the entire process even more challenging ${ }^{[1,5-8]}$.

With the appropriate knowledge of the age to initiate toilet training and acknowledging the factors 
that influence it, parents would be able to prevent many health issues related to voiding, urinary tract infections, and enuresis ${ }^{[1]}$.

There is a lack of scientific information regarding this topic; when reviewing the literature, only a few studies were conducted to determine the appropriate age to initiate toilet training and the factors associated with it ${ }^{[9]}$. No previous publication regarding this topic looking for healthy Saudi children. The lack of such scientific studies makes it difficult for mothers to plan an appropriate training program for their children. Thus, the aim of this study was to identify the appropriate age for initiating toilet training and assess the factors that could affect this learning process in Saudi Arabia.

\section{Methods}

This study was a cross-sectional study conducted in our institution. The study included mothers who attended various clinics at our institute. We included all male and female healthy Saudi children who had finished their toilet training. All mothers with non-Saudi children or children with any chronic illness were excluded. A sample size of 1000 children was determined using the equation of the single mean value, $n=\mathrm{Za}^{2} \mathrm{~S}^{\mathrm{s}} / \mathrm{d}^{2}$ $=(1.96)^{2}(6.57)^{2} / 0.5^{2}=663$; we expected a non-response of $20 \%, 663+132=795^{[10]}$. Ethics board approval was obtained for this study.

Data were obtained through self-administered questionnaires, which consisted of two parts. The first part included information and the demographic characteristics of the mothers. The second part included information about the child. The variables in the questionnaire were the mother's age, marital status, educational level, family income, child's age at the time of initiation, gender, number of siblings, and birth order (Fig. 1).

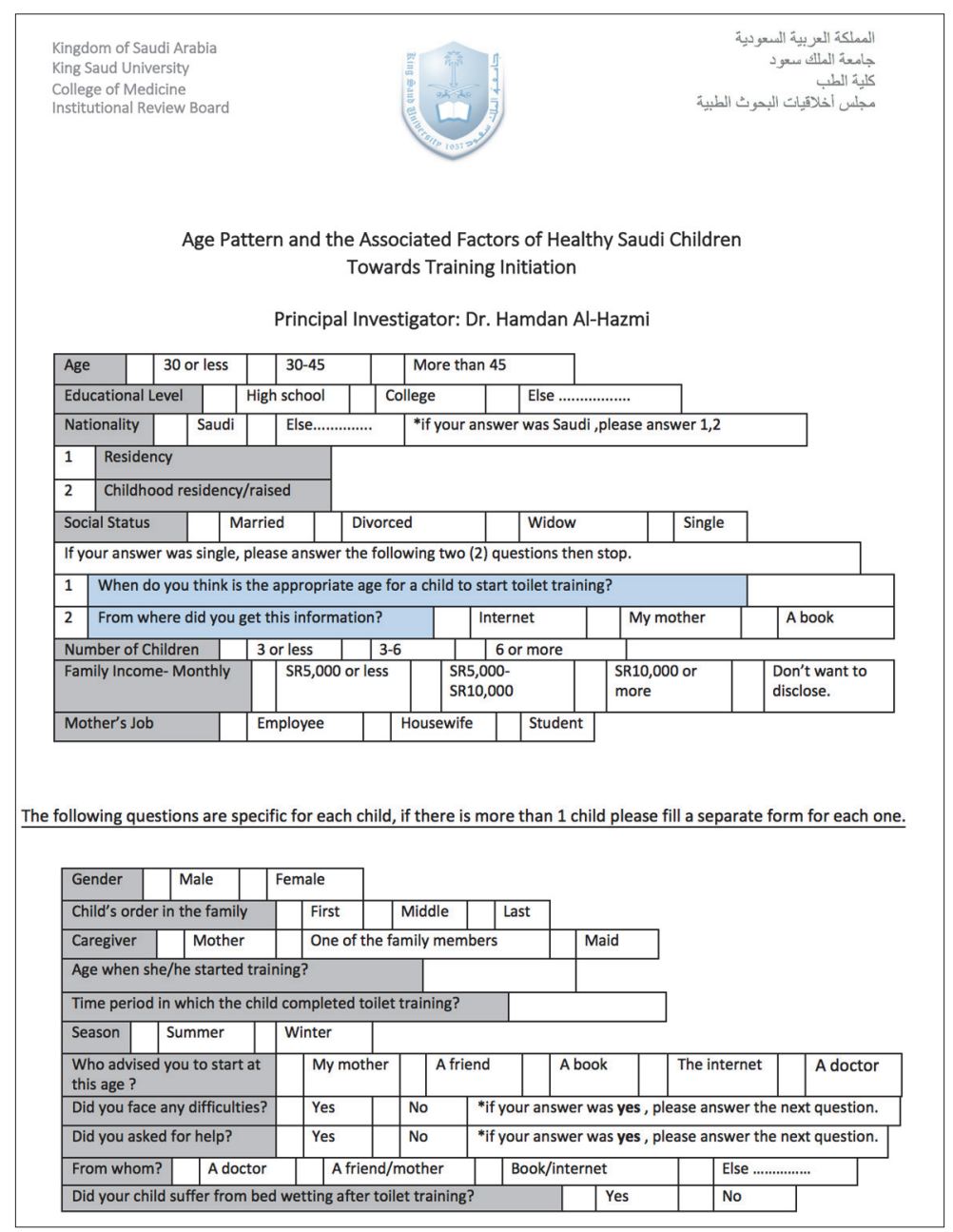

Figure 1. Questionnaire distributed to the mothers. 
After the data were collected, statistical analyses were performed using IBM SPSS Statistics for Windows, Version 21.0 (IBM Corp., Armonk, NY USA). The frequencies and percentages for all nominal variables were analyzed using one-way analysis of variance (ANOVA).

The mean age of the initiation of toilet training was compared with respect to all sociodemographic variables of mothers which included educational level, residence, and number of children, monthly income, and mother's occupation. A pilot study on 20 subjects was conducted to test the clarity and suitability of the questionnaire, and it took approximately 7-10 minutes to complete the questionnaire.

A clear and informed consent form was given to all participants explaining the purpose of the study and participant's right to withdraw at any time without any obligation towards the study team. Participant's anonymity was assured by assigning code numbers to each participant for the analysis only. No incentives or rewards were given to participants.

\section{Results}

Data were collected from the mothers of 1,477 child, and 477 children were excluded due to the following reasons: incomplete data, chronic health conditions, or those with a nationality other than Saudi.

The study participants were $50.5 \%$ females, and the remaining were males. Regarding the birth order, $52.4 \%(\mathrm{~N}=524)$ were middle children, $30.7 \%(\mathrm{~N}=307)$ were first-born, and $16.9 \%(\mathrm{~N}=169)$ were the youngest. Most of them were trained by the mother (96.2\%), and $3.8 \%$ were trained either by a family member or a nanny (Table 1).

The subjects of the study were primarily raised by a coupled household. The monthly income was above SAR10,000 in $36.1 \%$ of the families. Majority of the mothers (65.2\%) were housewives. More than half of the subject's mothers had a high school or college degree (63.6\%). Most of the study sample (87\%) resided in the central provinces of Saudi Arabia (Table 2).

For $60.1 \%$ of the mothers, the source of advice was a friend, book, the internet, or her own mother. The majority $(92.9 \%$,$) of the children were trained in$ summer (Table 1).
Table 1. Characteristics of the child.

\begin{tabular}{|l|c|}
\hline \multicolumn{1}{|c|}{ Variable } & $\mathbf{N}(\%)$ \\
\hline Gender & \\
Male & $495(49.50 \%)$ \\
Female & $505(50.50 \%)$ \\
\hline Order of Child & \\
$\quad$ First & $307(30.70 \%)$ \\
Middle & $524(52.40 \%)$ \\
Last & $169(16.90 \%)$ \\
\hline Caregiver & \\
Mother & $962(96.20 \%)$ \\
Family Member & $25(2.50 \%)$ \\
Maid & $13(1.30 \%)$ \\
\hline Season & \\
Summer & $920(92.00 \%)$ \\
Winter & $70(7.00 \%)$ \\
\hline Advice & \\
Yes & $601(60.10 \%)$ \\
No & $399(39.90 \%)$ \\
\hline Advice on when to start & \\
From mother & $494(80.06 \%)$ \\
\hline From friend & $65(10.53 \%)$ \\
\hline From a book & $31(5.02 \%)$ \\
From the internet & $24(3.89 \%)$ \\
From a doctor & $3(0.50 \%)$ \\
\hline Difficulties & $336(33.60 \%)$ \\
\hline Yes & $664(66.40 \%)$ \\
\hline No & $15(11.28 \%)$ \\
\hline Ask for help when faced by difficulties & $104(78.20 \%)$ \\
\hline From a doctor & $14(10.52 \%)$ \\
\hline From a friend/mother & $240(24.00 \%)$ \\
From book/internet & $760(76.00 \%)$ \\
\hline Bed wetting & \\
Yes & \\
No & \\
\hline
\end{tabular}

With respect to initiation age, $66.4 \%$ of the children were trained with no difficulty and by that we mean that they faced less bed wetting problem; a mean initiation age was 24.9 months and the mean duration of training was 5.1 months. Difficulty in training was seen in 33.6\%; the initiation age was 26.9 months, and the mean duration of training was 8.6 months (Tables 1 and 3). For 920 children trained in summer, 62 (67.5\%) were trained with no difficulties; less bed wetting problem. As for the winter season, $51.4 \%$ of the 70 participants were trained with no difficulties.

Of the 1,000 participants, $76 \%$ of them indicated no bed-wetting, with a mean initiation age of 25.1 months. For the remaining $24 \%$ of the participants who experienced bed-wetting, the mean initiation age was 27.2 months (Table 3 ). 
Table 2. Characteristics of the mother.

\begin{tabular}{|l|c|}
\hline \multicolumn{1}{|c|}{ Variable } & $\mathrm{N}(\%)$ \\
\hline $\begin{array}{l}\text { Educational Level } \\
\text { Illiterate }\end{array}$ & $80(8.00 \%)$ \\
Primary School & $142(14.20 \%)$ \\
Middle School & $142(14.20 \%)$ \\
High School & $235(23.50 \%)$ \\
College & $384(38.40 \%)$ \\
Masters & $17(1.70 \%)$ \\
\hline Residency & \\
Riyadh & $870(87.00 \%)$ \\
Outside Riyadh & $130(13.00 \%)$ \\
\hline No. of Children & \\
Less than 3 & $252(25.20 \%)$ \\
3-6 & $359(35.90 \%)$ \\
More than 6 & $387(38.70 \%)$ \\
\hline Monthly Income & \\
Less than SR5,000 & $214(21.40 \%)$ \\
SR5,000-SR10,000 & $224(22.40 \%)$ \\
More than SR10,000 & $361(36.10 \%)$ \\
Non-Disclosure & $201(20.10 \%)$ \\
\hline Mother's Job & \\
Student & $24(2.40 \%)$ \\
Worker & $324(32.40 \%)$ \\
Housewife & $652(65.20 \%)$ \\
\hline
\end{tabular}

The age of initiation of toilet training was positively correlated with the number of siblings $(p \leq 0.0001)$ and maternal education $(p=0.009)$. Factors such as the mother's occupation $(p=0.754)$, residence $(p$ value $=$ $0.886)$, birth order of the child ( $p=0.534)$, caregiver ( $p$ value $=0.427)$, and child's gender $(p=0.122)$ were not significant (Table 3 and 4).

Finally, we found that age of initiation $(p=0.002)$ and the season during which the child was trained ( $p$ $=0.006$ ) had a significant impact on the level of toilet training difficulty.

\section{Discussion}

The purpose of this study was to determine the appropriate age for initiating toilet training in healthy Saudi children and examine how different factors affect this training. After careful analysis of our data, we found that the mean age of initiation of toilet training in healthy Saudi children was 25.64 months, while the median was 24 months. Children who began training earlier-around the age of 25 months-faced fewer difficulties and bed wetting in comparison to those who started the training two months later (at 27

Table 3. Comparison of mean age of initiating toilet training and sociodemographic of the child.

\begin{tabular}{|c|c|c|c|c|}
\hline Variable & Mean age (SD) & Median (SD) & F/t-value & p-value \\
\hline $\begin{array}{l}\text { Gender } \\
\text { Male } \\
\text { Female }\end{array}$ & $\begin{array}{l}26.12(9.79) \\
25.17(9.15)\end{array}$ & $\begin{array}{l}30.50(13.8) \\
28.00(11.3)\end{array}$ & 1.58 & 0.122 \\
\hline $\begin{array}{l}\text { Order of Child } \\
\text { First } \\
\text { Middle } \\
\text { Last }\end{array}$ & $\begin{array}{l}26.06(9.55) \\
25.32(9.34) \\
25.85(9.79)\end{array}$ & $\begin{array}{l}30.25(11.8) \\
28.0(12.8) \\
30.0(13.5)\end{array}$ & 0.63 & 0.534 \\
\hline $\begin{array}{l}\text { Caregiver } \\
\text { Mother } \\
\text { Family Member } \\
\text { Maid }\end{array}$ & $\begin{array}{c}25.71(9.44) \\
23.32(10.75) \\
24.62(10.44) \\
\end{array}$ & $\begin{array}{l}30.0(12.5) \\
26.0(16.2) \\
39.0(12.3)\end{array}$ & 0.85 & 0.427 \\
\hline $\begin{array}{l}\text { Season } \\
\text { Summer } \\
\text { Winter }\end{array}$ & $\begin{array}{l}25.86(9.40) \\
22.96(9.31)\end{array}$ & $\begin{array}{c}30.0(12.4) \\
29.75(14.8)\end{array}$ & 2.49 & 0.590 \\
\hline $\begin{array}{c}\text { Advice } \\
\text { Yes } \\
\text { No }\end{array}$ & $\begin{array}{c}24.63(8.87) \\
27.16(10.16)\end{array}$ & $\begin{array}{l}30.0(12.6) \\
30.0(12.8)\end{array}$ & -4.18 & $<0.0001$ \\
\hline $\begin{array}{l}\text { Difficulties } \\
\text { Yes } \\
\text { No }\end{array}$ & $\begin{array}{l}26.93(9.12) \\
24.98(9.59)\end{array}$ & $\begin{array}{c}32.0(14.5) \\
27.25(11.2)\end{array}$ & 3.09 & 0.649 \\
\hline $\begin{array}{l}\text { Ask for help } \\
\text { Yes } \\
\text { No }\end{array}$ & $\begin{array}{l}27.42(8.82) \\
26.01(9.04)\end{array}$ & $\begin{array}{l}35.0(13.2) \\
30.0(14.0)\end{array}$ & 1.34 & 0.832 \\
\hline $\begin{array}{l}\text { Bed wetting } \\
\text { Yes } \\
\text { No }\end{array}$ & $\begin{array}{l}27.20(9.36) \\
25.14(9.47)\end{array}$ & $\begin{array}{l}31.0(14.6) \\
28.0(11.8)\end{array}$ & 2.94 & 0.869 \\
\hline
\end{tabular}


Age of Initiation and the Factors Associated with Toilet Training in Healthy Saudi Children H.H. Al-Hazmi et al.

Table 4. Comparison of mean age of initiating toilet training and sociodemographic of the mother.

\begin{tabular}{|l|c|c|c|c|}
\hline & Mean Age (SD) & Median (SD) & & p-value \\
\hline Educational Level & & & & \\
Illiterate & $24.89(11.52)$ & $27.0(11.19)$ & & 0.009 \\
Primary School & $25.05(9.39)$ & $30.0(11.08)$ & & \\
Middle School & $23.61(8.97)$ & $27.0(14.0)$ & 3.07 & \\
High School & $25.86(8.89)$ & $26.0(11.25)$ & & \\
College & $26.77(9.41)$ & $25.5(11.9)$ & & \\
Masters & $22.35(10.63)$ & $28.0(12.9)$ & & \\
\hline Residency & & & & \\
Riyadh & $25.81(9.41)$ & $28.0(11.4)$ & 0.02 & \\
Outside Riyadh & $24.5(9.91)$ & $33.0(13.8)$ & & \\
\hline Number of Children & $27.93(9.79)$ & $36.0(11.9)$ & & \\
Less than 3 & $25.95(9.57)$ & $27.5(11.25)$ & & \\
3-6 & $23.88(8.84)$ & $26.0(11.5)$ & & \\
More than 6 & $27.03(9.88)$ & $30.3(12.8)$ & & \\
\hline Monthly Income & $26.50(9.64)$ & $28.0(9.7)$ & & \\
Less than SR5,000 & $25.30(9.32)$ & $27.2(11.3)$ & & \\
SR5,000-SR10,000 & $23.81(8.86)$ & $27.0(13.2)$ & & \\
More than SR10,000 & & & & \\
Non-Disclosure & $26.38(10.05)$ & $30.0(10.6)$ & & \\
\hline Mother's Job & $25.90(9.61)$ & $24.0(9.02)$ & 0.28 & \\
Student & $25.48(9.40)$ & $27.0(12.3)$ & & \\
Worker & & & \\
Housewife & & & \\
\hline
\end{tabular}

months). Chiozza et al. ${ }^{[11]}$ noticed a high prevalence rate of enuresis when the toilet training started after age of 36 months (17.1\%) when compared to the age of toilet training before 25 (2.5\%) months and between 25 and 36 months (508\%) With these findings, we can conclude that 25 months is the appropriate age to initiate toilet training in healthy Saudi children. A previous study found that the training process is preferred to start at 24 months; which is one month earlier than what our findings show ${ }^{[12]}$. These findings are highly supported by both The American Academy of Pediatrics and The Canadian Pediatrics Society ${ }^{[13]}$.

The factors affecting the age of initiating toilet training can be classified into maternal and child factors. We found that mothers with a low educational level as illiterate mothers and mothers who completed only their primary or middle school, train their children earlier in comparison to highly educated mothers who graduated from high school, college, or masters, which was similar to the result of Tarhan et al's study ${ }^{[10]}$. Mother's occupation and the area of residence did not affect the age of initiating toilet training. We found that the more children the mother had, the earlier she started the training. This could be explained by mothers with more children having more experience and knowledge about the toilet training process and therefore training their children at an earlier age. No previous studies have mentioned the effect of the number of children on the age of toilet training initiation. However, a study showed a strong correlation between toilet training and whether a parent had previously trained more than one child ${ }^{[14]}$. Regarding family income and the age of toilet training, a previous study showed that family income is directly proportional to the age of toilet training initiation and this can be explained by the increased efforts of lowincome families to avoid expensive diapers ${ }^{[10,15]}$. Our study showed the opposite finding; family's monthly income and the age of starting toilet training were inversely related.

Regarding the child-related factors, a previous study showed a gender-specific effect on the starting age of toilet training, wherein females, on an average, were found to be three months ahead of males ${ }^{[2,4]}$. However, in our study, gender had no effect. Furthermore, our study revealed no influence of who trained the child (mother, family member, or nanny). There have been no previous studies examining this factor, which need to be addressed in more future studies. 
Several previous studies have reported links between late training and bladder trouble. Their results were that kids who suffered from bladder problems like bedwetting, and recurrent urinary tract infections at school age were trained for toilet training at an older age. One of these studies was a case-control study design to yield level 2 evidence. The objective of this study was to determine if later toilet training is associated with urge incontinence in children. The result was that initiation of toilet training after 32 months of age was associated with urge incontinence $(P=0.02)^{[16]}$.

Finally, we examined whether different seasons have an effect on the training process. It is known that Saudi Arabia has a desert climate, which is characterized by very high temperatures. Usually, when the weather is hot, children tend to urinate less frequently which makes it easier for mothers to initiate toilet training during this time. This could explain why $92 \%$ of the mothers in our study trained their children during summer.

Our study has some limitations, which include the presence of recall bias in the parents and the difficulty to remember the mother's age and family income at the time of toilet training period. Furthermore, the sample was collected from one institution, and most of the patients were from the central province, which could have led to a selection bias. The strength of our study is the large sample size, which helped us obtain a variety of information from families with different backgrounds, making our findings more applicable to our general population.

\section{Conclusions}

The mean age of toilet training among healthy Saudi children was similar to those reported in international studies. Summer was the preferred season to initiate training. Maternal education, the number of children, and socioeconomic status were found to play a major role in the initiation age of toilet training.

\section{Conflict of Interest}

The authors have no conflict of interest.

\section{Disclosure}

None of the authors received any type of commercial support either in forms of compensation or financial for this study. They have no financial interest in any of the products or devices, or drugs mentioned in this article.

\section{Ethical Approval}

Obtained.

\section{References}

[1] Mota DM, Barros AJ. Toilet training: methods, parental expectations and associated dysfunctions. J Pediatr (Rio J) 2008; 84(1): 9-17.

[2] Blum NJ, Taubman B, Nemeth N. Relationship between age at initiation of toilet training and duration of training: a prospective study. Pediatrics 2003; 111(4 Pt 1): 810-814.

[3] deVries MW, deVries MR. Cultural relativity of toilet training readiness: a perspective from East Africa. Pediatrics 1977; 60(2): 170-177.

[4] Schum TR, Kolb TM, McAuliffe TL, Simms MD, Underhill $R L$, Lewis M. Sequential acquisition of toilet-training skills: a descriptive study of gender and age differences in normal children. Pediatrics 2002; 109(3): E48.

[5] De Paepe H, Hoebeke P, Renson C, Van Laecke E, Raes A, Van Hoecke E, Van Daele J, Vande Walle J. Pelvic-floor therapy in girls with recurrent urinary tract infections and dysfunctional voiding. Br J Urol 1998; 81 Suppl 3: 109-113.

[6] De Paepe H, Renson C, Hoebeke P, Raese A, Van Laecke $E$, Vande Walle J. The role of pelvic-floor therapy in the treatment of lower urinary tract dysfunction in children. Scand J Urol Nephrol 2002; 36(4): 260-267.

[7] Polaha J, Warzak WJ, Ditmer-Mcmahon K. Toilet training in primary care: current practice and recommendations from behavioral pediatrics. J Dev Behav Pediatr 2002; 23(6): 424-429.

[8] Schmitt BD. Toilet training: Getting it right the first time. Contemp Pediatr 2004; 21(3): 105-122.

[9] Vermandel A, Van Kampen M, Van Gorp C, Wyndaele JJ. How to toilet train healthy children? A review of the literature. Neurourol Urodyn 2008; 27(3): 162-166.

[10] Tarhan H, Çakmak Ö, Akarken I, Ekin RG, Ün S, Uzelli D, Helvaci M, Aksu N, Yavaşcan Ö, Mutlubaş Özsan F, Cun S, Koç F, Özkarakaş Ö, Libey YÖ, Zorlu F. Toilet training age and influencing factors: a multicenter study. Turk J Pediatr 2015; 57(2): 172-176

[11] Chiozza ML, Bernardinelli L, Caione P, Del Gado R, Ferrara P, Giorgi PL, Montomoli C, Rottoli A, Vertucci P. An Italian epidemiological multicentre study of nocturnal enuresis. Br J Urol 1998; 81 Suppl 3: 86-89.

[12] Stadtler AC, Gorski PA, Brazelton TB. Toilet training methods, clinical interventions, and recommendations. American Academy of Pediatrics. Pediatrics 1999; 103(6 Pt 2): 13591368.

[13] Lang ME. Among healthy children, what toilet-training strategy is most effective and prevents fewer adverse events (stool withholding and dysfunctional voiding)?: Part B: Clinical commentary. Paediatr Child Health 2008; 13(3): 203-204. 
[14] Schum TR, McAuliffe TL, Simms MD, Walter JA, Lewis M, Pupp R. Factors associated with toilet training in the 1990s. Ambul Pediatr 2001; 1(2): 79-86.

[15] Horn IB, Brenner R, Rao M, Cheng TL. Beliefs about the appropriate age for initiating toilet training: are there racial and socioeconomic differences? J Pediatr 2006; 149(2): 165-168.

[16] Barone J, Jasutkar N, Schneider D. Later toilet training is associated with urge incontinence in children. J Pediatr Urol 2009; 5(6): 458-461. 


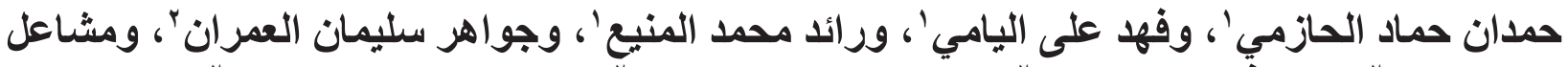

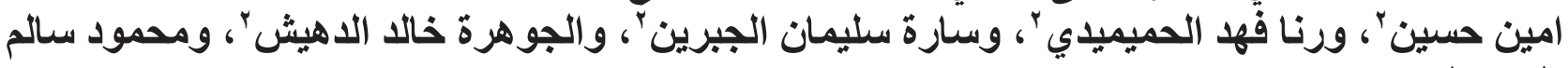

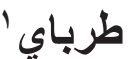

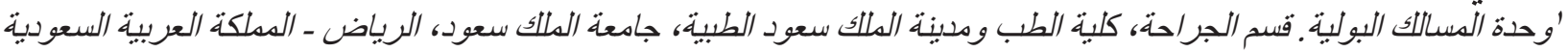

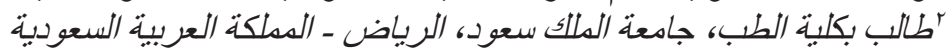

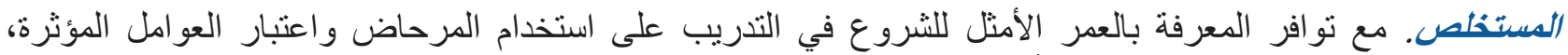

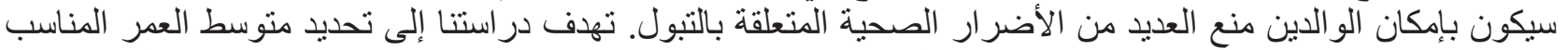

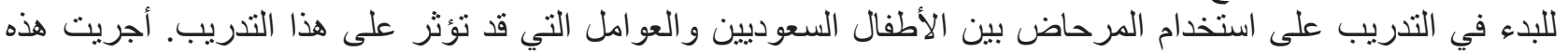

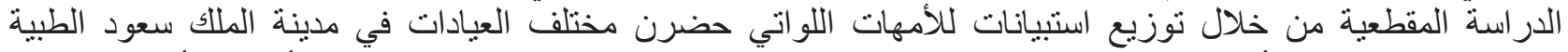

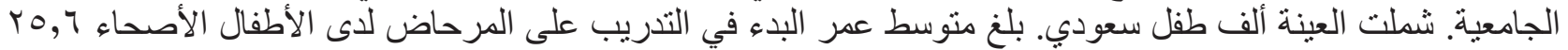

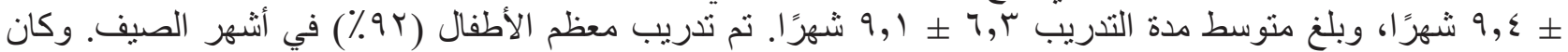

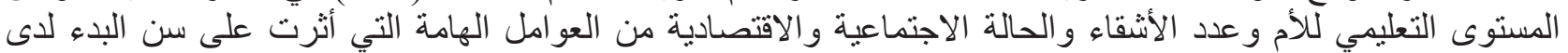

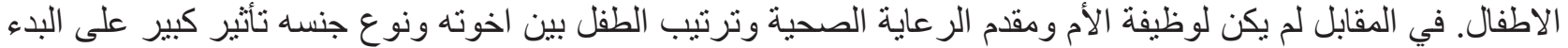

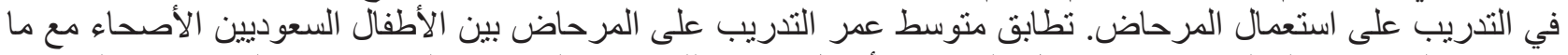

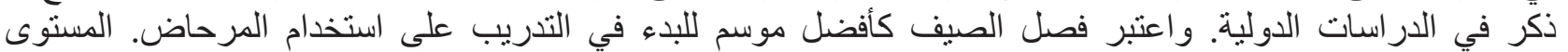
التعليمي للأم وعدد الإخوة والوضع الاجتماعي والاقتصادي لهم دور كبير في سن البدء في التدريب على استعمال المرحاض. 